\title{
The role of ABCB1 and ABCA1 in beta-amyloid clearance at the neurovascular unit in Alzheimer's disease
}

\section{Ayman EIAli and Serge Rivest*}

Laboratory of Neurosciences, Department of Molecular Medicine, Faculty of Medicine, CHU de Québec Research Center, Laval University, Québec, QC, Canada

\section{Edited by:}

Alessandro Prinetti, University of

Milano, Italy

Reviewed by:

Warren Thomas, Royal College of Surgeons in Ireland, Ireland

Natalia N. Nalivaeva, University of Leeds, UK

\section{*Correspondence:}

Serge Rivest, Laboratory of

Neurosciences, Department of

Molecular Medicine, Faculty of

Medicine, CHU de Québec

Research Center, Laval University,

2705 Laurier boul., Québec,

QC G1V 4G2, Canada.

e-mail: serge.rivest@crchul.ulaval.ca
Alzheimer's disease $(A D)$ is a progressive neurodegenerative disorder that affects elderly persons, evolving with age to reach severe cognitive impairment. Amyloid deposits and neurofibrillary tangles constitute the main pathological hallmarks of AD. Amyloid deposits are initiated by the excessive production and accumulation of beta-amyloid $(A \beta)$ peptides in the brain. The dysfunction of the Neurovascular Unit (NVU) has been proposed to be causative in $A D$ development, due to an impaired clearance of $A \beta$ from the brain. Cells forming the NVU express several Adenosine Triphosphate ATP-Binding Cassette (ABC) transporters, among which $A B C B 1$ and $A B C A 1$ play an important role in $A \beta$ processing. The drug transporter $A B C B 1$ directly transports $A \beta$ from the brain into the blood circulation, whereas the cholesterol transporter $A B C A 1$ neutralizes $A \beta$ aggregation capacity in an Apolipoprotein $E(A p o E)$-dependent manner, facilitating $A \beta$ subsequent elimination from the brain. In the present minireview, we will summarize the contribution of $A B C B 1$, and ABCA1 at the NVU in A clearance. Moreover, we will outline and discuss the possible collaboration of $A B C B 1$, and $A B C A 1$ at the NVU in mediating an efficient clearance of $A \beta$ from the brain.

Keywords: Alzheimer's disease, blood-brain barrier, neurovascular unit, ABCB1, ABCA1, apolipoprotein E, beta-amyloid clearance

\section{INTRODUCTION}

Alzheimer's disease $(\mathrm{AD})$ is a progressive neurodegenerative disorder that affects elderly persons. The pathogenesis of AD begins with mild memory deficits and evolves to reach total cognitive impairment and loss of executive functions (de Souza et al., 2009). It is now widely accepted that amyloid deposits and neurofibrillary tangles formation constitutes the core pathological hallmarks of AD (Selkoe, 2002). The sequential proteolytic cleavage of the Amyloid Precursor Protein (APP) produces beta-amyloid (A $\beta$ ) peptides, namely $\mathrm{A} \beta_{1-40}$ and $\mathrm{A} \beta_{1-42}$ (Hardy and Selkoe, 2002), which oligomerize to form small oligomers of $2-12$ peptides (i.e., $A \beta$ oligomers), and aggregate leading to $A \beta$ plaques generation (Haass and Selkoe, 2007). Although the correlation between $A \beta$ parenchymal deposition and cognitive decline still remains controversial, the detrimental role of soluble $A \beta$ oligomers in the brain of AD patients (Lue et al., 1999) and in mouse models of $\mathrm{AD}$ (Cheng et al., 2007) has been demonstrated.

In more than $95 \%$ of $\mathrm{AD}$ cases, several environmental and genetic factors that influence $A \beta$ processing have been reported to contribute in $\mathrm{AD}$ development (i.e., sporadic $\mathrm{AD}$ ), among which $A \beta$ clearance and elimination from the brain play a central role (Hardy and Selkoe, 2002). The remaining AD cases are caused by an excessive $A \beta$ production in the brain due to mutations in either $A P P$ gene or the enzymes involved in its proteolytic cleavage (i.e., familial AD) (Levy-Lahad et al., 1995; Sherrington et al., 1995).

The levels of soluble $A \beta$ oligomers in the brain play a crucial role in $\mathrm{AD}$ development, because their accumulation in brain parenchyma causes neuronal dysfunction that have been shown to take place even before the neurodegeneration cascade (Haass and Selkoe, 2007). In parallel, the early accumulation of $A \beta$ oligomers in cerebral microvessels causes vascular dysfunction and contributes to the development of Cerebral Amyloid Angiopathy (CAA), which takes place in $80 \%$ of $\mathrm{AD}$ cases (Bell and Zlokovic, 2009). Interestingly, microvascular dysfunction has been reported at the early stages of AD pathogenesis (Zlokovic, 2005), outlining a central role of cerebrovascular dysfunction in $\mathrm{AD}$ development (Pimentel-Coelho and Rivest, 2012). Indeed, abnormalities at the Blood-Brain Barrier (BBB) have been reported in AD (Desai et al., 2007), supporting this hypothesis.

The BBB constitutes a physical barrier separating the peripheral circulation from the central nervous system (CNS), and plays a central and major role in controlling brain homeostasis and regulating brain microenvironment, by (1) precisely adjusting nutrient and oxygen delivery based on brain needs, (2) removing toxic metabolites from the brain into the blood, (3) protecting the brain from endogenous and exogenous toxic molecules, and (4) supporting parenchymal tissue viability (Löscher and Potschka, 2005). The BBB adopts a special phenotype characterized by a high transendothelial electrical resistance (TEER), thus preventing the free passage of blood-borne molecules and cells from brain entry (Zlokovic, 2008). Anatomically, the BBB is constituted by specialized endothelial cells that actively interact with Extracellular Matrix (ECM) proteins that form the perivascular space, pericytes, astrocytes, microglia and neurons, forming the neurovascular unit (NVU), which is the functional unit of the BBB (Zlokovic, 2011). The NVU has two functionally distinct sides, the luminal side facing the blood circulation, and the 
abluminal side facing the brain parenchyma (Hermann and ElAli, 2012). To fulfill its role in controlling brain homeostasis and regulating brain microenvironment, the cells forming the NVU are complemented by sophisticated active transport systems, such as ion channels, pumps, receptors, and transporters, among which are the transmembrane transporters belonging to Adenosine Triphosphate-Binding Cassette (ABC) transporter family.

The ABC transporter family consists essentially of 48 proteins in humans, which are subdivided into 7 sub-families (ABC1, MDR/TAP, MRP, ALD, OABP, GCN20, White) (de Lange, 2004; Leslie et al., 2005). Initially, ABC transporters were discovered by oncologists to be responsible for chemotherapy resistance (Biedler and Riehm, 1970). ABC transporters use energy generated from ATP hydrolysis to transport substrates across cell membranes (ElAli and Hermann, 2011), and have overlapping affinity for many lipophilic and amphipathic molecules, therefore physiologically considered as cell detoxification systems (de Lange, 2004). ABC transporters, depending on the sub-family, act either as gatekeepers by protecting organs from toxic compounds, or as transporters of bioactive molecules produced by cells (Leslie et al., 2005). Two ABC transporters have been shown to play important roles in $\mathrm{AD}$ pathogenesis; (1) $\mathrm{ABC}$ transporter subfamily B member 1 (ABCB1; i.e., Multi Drug Resistance Protein; Mdr-1) that acts as an efflux pump of xenobiotic molecules, and (2) the ABC transporter sub-family A member 1 (ABCA1; i.e., Cholesterol Efflux Regulatory Protein; CERP) that acts as an efflux pump for cholesterol and phospholipids from cell membranes to Apolipoprotein E (ApoE) and ApoA-I (Wahrle et al., 2005; Kuhnke et al., 2007).

Two main mechanisms govern $A \beta$ clearance at the NVU, $A \beta$ degradation by specialized enzymes, and $A \beta$ transport across the BBB, from the brain into blood circulation (Nalivaeva et al., 2012; Sagare et al., 2012). Recently, it has been proposed that impaired $A \beta$ transport, elimination, and clearance across the $\mathrm{BBB} / \mathrm{NVU}$ constitute key steps in $\mathrm{AD}$ pathogenesis, as it causes an excessive accumulation of $A \beta$ in brain parenchyma, inducing neuronal dysfunction and favoring $A \beta$ plaques formation (Zlokovic, 2008). This hypothesis suggests that the dysfunction of the $\mathrm{BBB} / \mathrm{NVU}$ causatively contributes to the pathogenesis of AD (Zlokovic, 2011), which is now under intense investigation. Several ABC transporters have been reported to be involved in $A \beta$ processing, transport, and clearance at the NVU (Abuznait and Kaddoumi, 2012), among which ABCB1, and ABCA1 are the most studied and characterized. As such, in this minireview, we would like firstly to summarize the known roles of $A B C B 1$ and ABCA1 expressed by the different cell types forming the NVU in $A \beta$ clearance from brain parenchyma and microvessels into blood circulation, secondly to propose possible mechanisms for $A \beta$ clearance through the NVU based on the existing literature, and finally to discuss the potential of $\mathrm{ABCB} 1$ and $\mathrm{ABCA} 1$ modulation as a new therapeutic strategy in $\mathrm{CAA}$, and $\mathrm{AD}$ treatment.

\section{$\beta$-AMYOID CLEARANCE BY BRAIN ENDOTHELIAL CELLS}

Being the first line of defense, brain endothelial cells express high level of $\mathrm{ABC}$ transporters, especially drug transporters that extrude toxic molecules from the brain, namely $A B C B 1$. ABCB1 is highly expressed at the luminal side of brain endothelial cells, and is considered as marker of BBB maturity and functionality (Hermann and ElAli, 2012). It has been reported that soluble $A \beta$ is transported across brain endothelial cells and eliminated from the brain into blood circulation, mainly via the lowdensity lipoprotein-related protein-1 (LRP-1) in collaboration with ABCB1 (Zlokovic, 2008). For instance, it has been shown that $A \beta$ binds to $A B C B 1$, and that the latter is directly involved in its active transport (Lam et al., 2001). In parallel, LRP-1 can bind directly $A \beta$ or via ligands that bind $A \beta$, such as ApoE (Yamada et al., 2008). As such, LRP-1/ABCB1 seems to form an efficacious and complete transport system that coordinates $A \beta$ transport and elimination from the brain. Interestingly, the pharmacological inhibition of $\mathrm{ABCB} 1$ decreased $\mathrm{A} \beta$ clearance in vitro (Lam et al., 2001; Kuhnke et al., 2007), outlining the direct involvement of $\mathrm{ABCB} 1$ in $\mathrm{A} \beta$ clearance. These in vitro observations were confirmed by in vivo studies where $a b c a 1 a / b^{-/-}$knockout mice intracerebrally injected with $A \beta$ exhibited reduced clearance of these peptides compared to control littermates (Cirrito et al., 2005). In human, experiments on post-mortem tissue samples of $\mathrm{AD}$ patients showed decreased expression levels of $\mathrm{ABCB} 1$ in brain endothelial cells of microvessels that surround $A \beta$ deposits (Vogelgesang et al., 2002), and almost no expression of ABCB1 in brain endothelial cells was detected in post-mortem tissue samples obtained from CAA patients (Vogelgesang et al., 2004).

It is noteworthy, that ABCB1 expression in brain endothelial cells decreases with physiological aging, as shown in long-lived $\mathrm{B}-\mathrm{N} / \mathrm{F}$ rats, which interestingly caused brain accumulation of exogenously administered $A \beta$ (Silverberg et al., 2010). In human brain, $A B C B 1$ expression has been reported to decrease in elderly subjects (Bartels et al., 2009). This observation is highly important, because the decreased expression of ABCB1 impeded NVU's capacity in acting as a gatekeeper for the brain, allowing endogenous and exogenous toxins, like $A \beta$, to accumulate in the brain, thus inducing neuronal dysfunction. Taken together, these reports and studies strongly suggest and advocate a central role of $\mathrm{ABCB} 1$ expression in brain endothelial cells in $\mathrm{AD}$ pathogenesis, by affecting $A \beta$ transport across the brain endothelium.

In contrast to $A B C B 1, A B C A 1$ does not directly bind and extrude $\mathrm{A} \beta$. In brain endothelial cells, $\mathrm{ABCA} 1$ is expressed at the abluminal side of the endothelium (Panzenboeck et al., 2002). Experiments conducted in $a b c a 1^{-/-}$knock-out mice showed that ABCBA1 controls $A \beta$ degradation fate and its ability to form aggregates, via an ApoE dependent manner, thus enhancing its clearance from the brain (Akanuma et al., 2008). Being a regulator of cholesterol efflux, ABCA1 controls protein levels of ApoE and its lipidation state, which constitutes an important factor in the capacity of ApoE to efficiently bind $A \beta$ (Tokuda et al., 2000). As such, highly lipidated ApoE binds more efficiently $A \beta$ and diminishes its capacity to aggregate by modulating its conformation (Wahrle et al., 2004; Holtzman et al., 2012). Interestingly, it was reported that PDAPP/abcal transgenic mice that overexpress $A B C A 1$, have reduced $A \beta$ deposits in brain parenchyma compared to their littermates, and almost complete absence of vascular $A \beta$ deposits (Wahrle et al., 2008), outlining an efficient elimination of $A \beta$ across the NVU. This observation is intriguing giving the fact that $\mathrm{ABCA1}$ does not physically bind and eliminate $\mathrm{A} \beta$. As such, we propose a mechanism via which the abluminal 
ABCA1, upon its activation, induces efficient ApoE lipidation, thus facilitating $A p o E / A \beta$ interaction in the perivascular space, making $A \beta$ more accessible to LRP-1/ABCB1 transport system at the NVU (Figure 1).

\section{$\beta$-AMYLOID CLEARANCE BY PERICYTES}

Pericytes are tightly associated to the abluminal side of brain microvessels and covers approximately $25 \%$ of their circumference (Hellström et al., 2001). Brain pericytes act as vascular smooth cells (vSMC) by expressing several receptors of vasoactive molecules, therefore playing a major role in controlling brain microvascular tone (Armulik et al., 2011). Pericytes play an important role in regulating endothelial cell proliferation, survival, and migration (Hellström et al., 2001), and are required for BBB formation and induction by down-regulating genes associated with vascular permeability (Daneman et al., 2010), and inducing the functional activity of ABCB1 in brain endothelial cells (Al Ahmad et al., 2011). Moreover, some reports showed that brain pericytes behave like immune cells under stress by expressing the macrophage markers ED-2 and CD11b, and have some basal phagocytosis capacities (Kovac et al., 2011). Besides, it was reported that a high concentration of $A \beta$ induces pericytes apoptosis (Verbeek et al., 1997), and differentially regulates pericytic genes at lower A $\beta$ concentrations (Rensink et al., 2004). Interestingly, it has been shown that pericytes express LRP-1, and this expression has been shown to be modulated by $A \beta$ loading (Wilhelmus et al., 2007). In parallel, ABCB1 has been reported to be expressed in pericytes (Berezowski et al., 2004; Bendayan

\section{BLOOD}

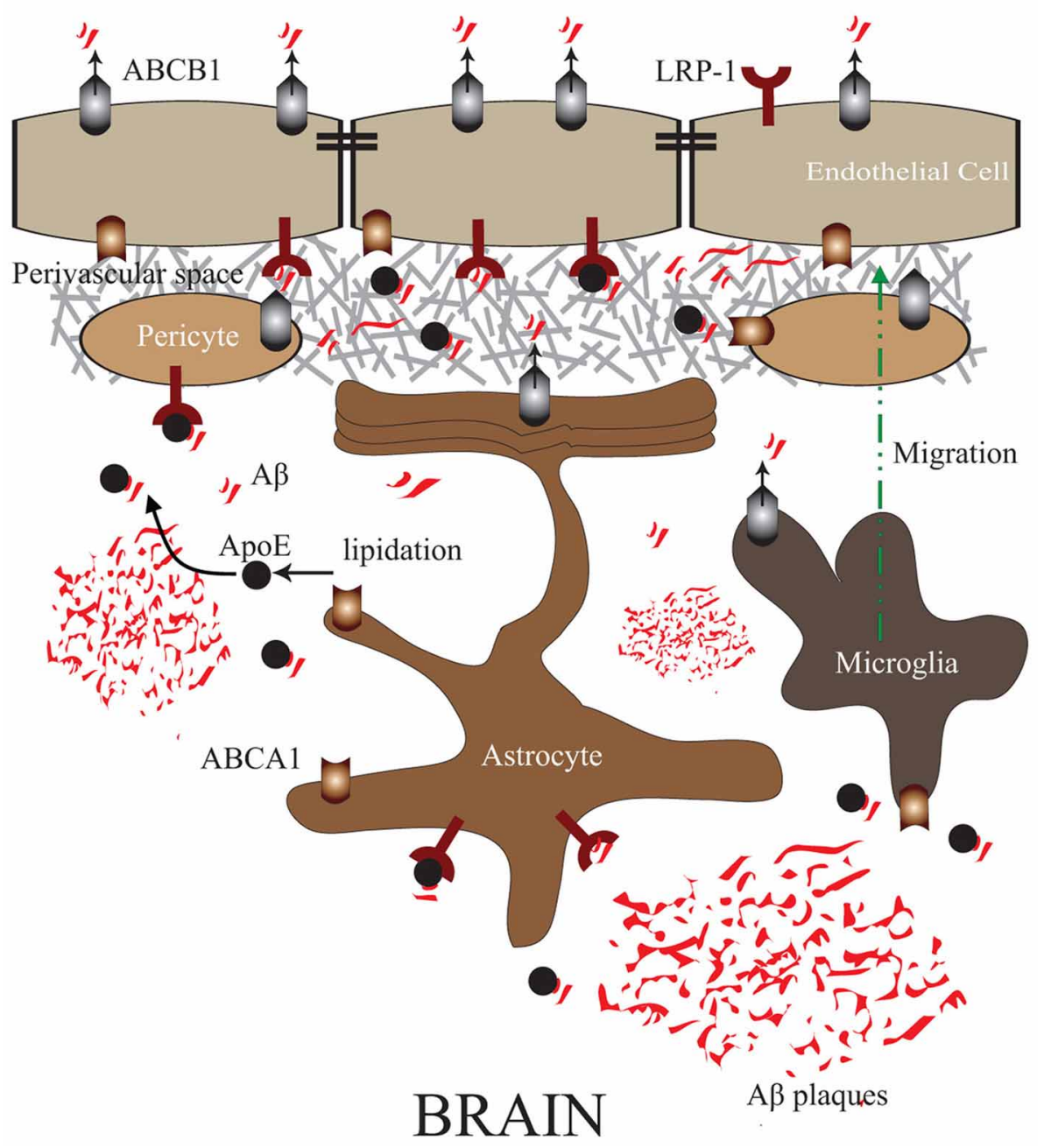

FIGURE 1 | ABCA1/ABCB1 Transport Systems in the NVU: Proposed mechanism via which ABCA1/ApoE-LRP-1/ABCB1 systems in the NVU cooperate in order to efficiently mediate $A \beta$ clearance from brain parenchyma, and microvessels into blood circulation. ABCA1 in brain endothelial cells, pericytes, astrocytes, and microglial cells enhances ApoE lipidation, and with the collaboration of $A B C B 1$ facilitates $A \beta$ trafficking into the perivascular space, where it can be subsequently eliminated into blood circulation via LRP-1/ABCB1 in brain endothelial cells. 
et al., 2006). Taken together, these reports would suggest a potential role of the LRP-1/ABCB1 system in A $\beta$ clearance, a hypothesis that merits further investigations. Recently, it has been reported that pericytes express ABCA1, which upon stimulation enhance ApoE lipidation without affecting the fate of the internalized $\mathrm{A} \beta$ (Saint-Pol et al., 2012). As such, it is very probable that the stimulation of ABCA1 in pericytes, in parallel to ABCA1 at the abluminal side of brain endothelial cells, further enhances ApoE production and lipidation at the perivascular space, diminishing the capacity of $A \beta$ to aggregate in the perivascular space, and makes soluble $A \beta$ more accessible to be cleared across the NVU (Figure 1).

\section{$\beta$-AMYLOID CLEARANCE BY ASTROCYTES}

Astrocyte endfeet cover up to $90 \%$ of brain microvessels, and play an essential role in inducing BBB features (Davson and Oldendorf, 1967). The presence of astrocytes is a prerequisite for $\mathrm{BBB}$ integrity by enhancing tight junction proteins expression and BBB functionality by inducing the expression of ABCB1 at the luminal side of brain endothelial cells (Abbott et al., 2006). Although the physiological level of ABCB1 expression in astrocytes is low and the exact role of this basal expression is totally unknown, it is well reported that under pathophysiological conditions, such as epilepsy, ABCB1 expression is highly increased and specifically at the endfeet of reactive astrocytes, thus playing a major role in epileptic drug resistance (Sisodiya et al., 2002). The expression levels of ABCB1 in astrocytes in $\mathrm{AD}$ are still to be investigated, but it would be highly surprising that its expression in astrocytes does not change in AD.

Nonetheless, it has been shown that astrocytes close to plaques express LRPs and internalize $A \beta$ in an ApoE dependent manner (Arélin et al., 2002). The fate of $A \beta$ uptaken by astrocytes is still elusive, as it has been proposed that the accumulation of $A \beta$ can induce astrocytes dysfunction and contribute in the pathogenesis of AD (Nagele et al., 2003), or can be degraded (Wyss-Coray et al., 2003). Giving the fact that most intra-astrocytic $A \beta$ are of neuronal origin (Nagele et al., 2003), and internalized mainly from cored plaques (Arélin et al., 2002), it is very probable, although speculative, that portions of internalized $\mathrm{A} \beta$ are trafficked toward endfeet facing the abluminal side of brain endothelial cells, where they can be eliminated in the perivascular space and be cleared into blood circulation by the brain endothelial cells transport system, LRP-1/ABCB1.

In addition, astrocytes express high level of ABCA1, which as discussed above, plays a crucial role in the lipidation of astrocyte-produced ApoE (Wahrle et al., 2004), thus facilitating $\mathrm{A} \beta$ clearance by reducing $\mathrm{A} \beta$ aggregation (Holtzman et al., 2012). As such, astrocytes contribute in $A \beta$ clearance by making $A \beta$ more diffusible and more accessible to be cleared across the NVU (Figure 1).

\section{$\beta$-AMYLOID CLEARANCE BY MICROGLIA}

Microglial cells are the resident macrophages of the brain, constituting the first line of immune defense (Bellavance and Rivest, 2012). They act as continuous scavengers at the brain for $A \beta$ plaques, debris, apoptotic neurons (Naert and Rivest, 2011), surveying closely the smallest changes in the brain, and exhibiting significant phagocytosis capacities (Naert and Rivest, 2011). Although microglial cells are closely associated to $A \beta$ plaques in vivo, they do not appear to be efficient in clearing $A \beta$ deposits (Bolmont et al., 2008). Interestingly, microglial cells are still able to internalize both fibrillar $A \beta$ and soluble $A \beta$ which would suggest that internalization of $A \beta$ is not always accompanied by their degradation (Pan et al., 2011), outlining a different fate for these internalized $A \beta$ peptides. Similar to astrocytes, ABCB1 expression in microglia is low under physiological conditions (Wolf et al., 2012), but has been shown to be increased in epilepsy (Löscher and Potschka, 2005). The expression levels of ABCB1 in microglia cells in $\mathrm{AD}$ are totally unknown, but as microglial cells have the ability to internalize $A \beta$, it would be probable that ABCB1 in microglial cells plays a role in $A \beta$ transport. Similar to astrocytes, microglial cells express high levels of ABCA1 and contribute to ApoE production and lipidation in the brain, therefore contribute to $\mathrm{A} \beta$ clearance (Hirsch-Reinshagen et al., 2004) (Figure 1).

\section{PHARMACOLOGICAL MODULATION OF ABCB1 AND ABCA1 AT THE LEVEL OF NVU AS A THERAPEUTIC APPROACH}

ABCB1 plays a key role in $A \beta$ transport and clearance at different levels of the NVU. This role could be highly relevant in developing new strategies to treat $\mathrm{AD}$. Indeed, $\mathrm{ABCB} 1$ is induced following activation of the Orphan Nuclear Receptor (ONR), Pregnane X Receptor (PXR) in brain microvessels of humans (Bauer et al., 2006). A clinical study conducted in AD patients with mild cognitive deficits concluded that both doxycycline and rifampicin efficaciously reduce the cognitive decline in treated patients (Loeb et al., 2004), possibly and partly via a mechanism involving $\mathrm{ABCB} 1$, as both molecules have been reported to induce ABCB1 expression (Wolf et al., 2012). In parallel, it has been shown, in a mouse model of $\mathrm{AD}$ that inducing the expression of $\mathrm{ABCB} 1$ by stimulating PXR, highly decreased $\mathrm{A} \beta$ brain accumulation (Hartz et al., 2010). More recently, it has been reported that the stimulation of Retinoid X Receptor (RXR) using the agonist bexarotene in a mouse model of $\mathrm{AD}$ enhanced soluble $\mathrm{A} \beta$ clearance in an ApoE dependent manner (Cramer et al., 2012). It is noteworthy that RXR binds as a heterodimer with PXR to the PXR-responsive element regulating $a b c b 1$ gene expression (Geick et al., 2001). Finally, ABCB1 constitutes a main target gene of nuclear receptors, as even the stimulation of Liver X Receptor (LXR) with agonists has been reported to potently induce ABCB1 expression in brain microvessels (ElAli and Hermann, 2012). The induction of $\mathrm{ABCB} 1$ by nuclear receptors' stimulation could be a highly attractive strategy, because it allows in parallel to induce the expression of ABCA1 and ApoE, and the lipidation of the latter (Koldamova et al., 2003; Donkin et al., 2010).

\section{CONCLUSION}

The expression of $\mathrm{ABCB} 1$ and $\mathrm{ABCA} 1$ in all cells forming the NVU is of high importance, because it would constitute an elegant mechanism via which the ABCA1/ApoE and LRP-1/ABCB1 systems work in concert and cooperate to facilitate $A \beta$ transport from plaques towards brain microvessels, and its subsequent clearance into blood circulation. Most of the parenchymal deposits are relatively far from functional brain microvessels, 
as such the mechanism proposed here suggests $A \beta$ trafficking towards the perivascular space and abluminal side of brain endothelial cells, in order to be cleared into blood circulation. As such, we believe that the up-regulation and function of ABCB1 and ABCA1, not only in brain endothelia, but in all cells forming the NVU (Figure 1), may enhance $A \beta$ clearance from the brain more efficiently, consequently reducing $A \beta$ deposition in both

\section{REFERENCES}

Abbott, N. J., Rönnbäck, L., and Hansson, E. (2006). Astrocyteendothelial interactions at the blood-brain barrier. Nat. Rev. Neurosci. 7, 41-53.

Abuznait, A. H., and Kaddoumi, A. (2012). Role of ABC transporters in the pathogenesis of Alzheimer's disease. A.C.S. Chem. Neurosci. 3, 820-831.

Akanuma, S., Ohtsuki, S., Doi, Y., Tachikawa, M., Ito, S., Hori, S., et al. (2008). ATP-binding cassette transporter A1 (ABCA1) deficiency does not attenuate the brain-to-blood efflux transport of human amyloidbeta peptide (1-40) at the bloodbrain barrier. Neurochem. Int. 52, 956-961.

Al Ahmad, A., Taboada, C. B., Gassmann, M., and Ogunshola, O. O. (2011). Astrocytes and pericytes differentially modulate blood-brain barrier characteristics during development and hypoxic insult. J. Cereb. Blood Flow Metab. 31, 693-705.

Arélin, K., Kinoshita, A., Whelan, C. M., Irizarry, M. C., Rebeck, G. W., Strickland, D. K., et al. (2002). LRP and senile plaques in Alzheimer's disease: colocalization with apolipoprotein $\mathrm{E}$ and with activated astrocytes. Brain Res. Mol. Brain Res. 104, 38-46.

Armulik, A., Genové, G., and Betsholtz, C. (2011). Pericytes: developmental, physiological, and pathological perspectives, problems, and promises. Dev. Cell 21, 193-215.

Bartels, A. L., Kortekaas, R., Bart, J., Willemsen, A. T., de Klerk, O. L., de Vries, J. J., et al. (2009). Blood-brain barrier P-glycoprotein function decreases in specific brain regions with aging: a possible role in progressive neurodegeneration. Neurobiol. Aging 30, 1818-1824.

Bauer, B., Yang, X., Hartz, A. M., Olson, E. R., Zhao, R., Kalvass, J. C., et al. (2006). In vivo activation of human pregnane $\mathrm{X}$ receptor tightens the blood-brain barrier to methadone through P-glycoprotein up-regulation. Mol. Pharmacol. 70, 1212-1219.
Bell, R. D., and Zlokovic, B. V. (2009). Neurovascular mechanisms and blood-brain barrier disorder in Alzheimer's disease. Acta Neuropathol. 118, 103-113.

Bellavance, M. A., and Rivest, S. (2012). The neuroendocrine control of the innate immune system in health and brain diseases. Immunol. Rev. 248, 36-55.

Bendayan, R., Ronaldson, P. T., Gingras, D., and Bendayan, M. (2006). In situ localization of Pglycoprotein $(\mathrm{ABCB} 1)$ in human and rat brain. J. Histochem. Cytochem. 54, 1159-1167.

Berezowski, V., Landry, C., Dehouck, M. P., Cecchelli, R., and Fenart, L. (2004). Contribution of glial cells and pericytes to the mRNA profiles of P-glycoprotein and multidrug resistance-associated proteins in an in vitro model of the blood-brain barrier. Brain Res. 1018, 1-9.

Biedler, J. L., and Riehm, H. (1970). Cellular resistance to actinomycin $\mathrm{D}$ in Chinese hamster cells in vitro: cross-resistance, radioautographic, and cytogenetic studies. Cancer Res. 30, 1174-1184.

Bolmont, T., Haiss, F., Eicke, D., Radde, R., Mathis, C. A., Klunk, W. E., et al. (2008). Dynamics of the microglial/amyloid interaction indicate a role in plaque maintenance. J. Neurosci. 28, 4283-4292.

Cheng, I. H., Scearce-Levie, K., Legleiter, J., Palop, J. J., Gerstein, H., Bien-Ly, N., et al. (2007). Accelerating amyloid-beta fibrillization reduces oligomer levels and functional deficits in Alzheimer disease mouse models. J. Biol. Chem. 282, 23818-23828.

Cirrito, J. R., Deane, R., Fagan, A. M., Spinner, M. L., Parsadanian, M., Finn, M. B., et al. (2005). P-glycoprotein deficiency at the blood-brain barrier increases amyloid-beta deposition in an Alzheimer disease mouse model. J. Clin. Invest. 115, 3285-3290.

Cramer, P. E., Cirrito, J. R., Wesson, D. W., Lee, C. Y., Karlo, J. C., Zinn, A. E., et al. (2012). ApoE-directed therapeutics rapidly clear $\beta$-amyloid and reverse deficits in $\mathrm{AD}$ mouse models. Science 335, 1503-1506.

parenchyma and perivascular space. This mechanism provides a novel approach to be considered in parallel with other strategies in treating CAA and $\mathrm{AD}$.

\section{ACKNOWLEDGMENTS}

This work was supported by the Canadian Institutes in Health Research (CIHR), and Canadian Stroke Network.

Daneman, R., Zhou, L., Kebede, A. A., and Barres, B. A. (2010). Pericytes are required for blood-brain barrier integrity during embryogenesis. Nature 468, 562-566.

Davson, H., and Oldendorf, W. H. (1967). Symposium on membrane transport. Transport in the central nervous system. Proc. R. Soc. Med. 60, 326-329.

de Lange, E. C. (2004). Potential role of $\mathrm{ABC}$ transporters as a detoxification system at the blood-CSF barrier. Adv. Drug Deliv. Rev. 56, 1793-1809.

de Souza, L. C., Sarazin, M., Goetz, C., and Dubois, B. (2009). Clinical investigations in primary care. Front. Neurol. Neurosci. 24, 1-11. doi: 10.1159/000197897

Desai, B. S., Monahan, A. J., Carvey, P. M., and Hendey, B. (2007). Blood-brain barrier pathology in Alzheimer's and Parkinson's disease: implications for drug therapy. Cell Transplant. 16, 285-299.

Donkin, J. J., Stukas, S., HirschReinshagen, V., Namjoshi, D., Wilkinson, A., May, S., et al. (2010). ATP-binding cassette transporter Al mediates the beneficial effects of the liver X receptor agonist GW3965 on object recognition memory and amyloid burden in amyloid precursor protein/presenilin 1 mice. J. Biol. Chem. 285, 34144-34154.

ElAli, A., and Hermann, D. M. (2011). ATP-binding cassette transporters and their roles in protecting the brain. Neuroscientist 17, 423-436.

ElAli, A., and Hermann, D. M. (2012). Liver X receptor activation enhances blood-brain barrier integrity in the ischemic brain and increases the abundance of ATP-binding cassette transporters $\mathrm{ABCB} 1$ and $\mathrm{ABCC} 1$ on brain capillary cells. Brain Pathol. 22, 175-187.

Geick, A., Eichelbaum, M., and Burk, O. (2001). Nuclear receptor response elements mediate induction of intestinal MDR1 by rifampin. J. Biol. Chem. 276, 14581-14587.

Haass, C., and Selkoe, D. J. (2007). Soluble protein oligomers in neurodegeneration: lessons from the Alzheimer's amyloid beta-peptide. Nat. Rev. Mol. Cell Biol. 8, 101-112.
Hardy, J., and Selkoe, D. J. (2002). The amyloid hypothesis of Alzheimer's disease: progress and problems on the road to therapeutics. Science 297, 353-356.

Hartz, A. M., Miller, D. S., and Bauer, B. (2010). Restoring bloodbrain barrier P-glycoprotein reduces brain amyloid-beta in a mouse model of Alzheimer's disease. Mol. Pharmacol. 77, 715-723.

Hellström, M., Gerhardt, H., Kalén, M., Li, X., Eriksson, U., Wolburg, H., et al. (2001). Lack of pericytes leads to endothelial hyperplasia and abnormal vascular morphogenesis. J. Cell Biol. 153, 543-553.

Hermann, D. M., and ElAli, A. (2012). The abluminal endothelial membrane in neurovascular remodeling in health and disease. Sci. Signal. 5:re4. doi: 10.1126/scisignal. 2002886

Hirsch-Reinshagen, V., Zhou, S. Burgess, B. L., Bernier, L., McIsaac, S. A., Chan, J. Y., et al. (2004). Deficiency of ABCA1 impairs apolipoprotein E metabolism in brain. J. Biol. Chem. 279, 41197-41207.

Holtzman, D. M., Herz, J., and Bu, G. (2012). Apolipoprotein e and apolipoprotein e receptors: normal biology and roles in Alzheimer disease. Cold Spring Harb. Perspect. Med. 2:a006312. doi: 10.1101/ cshperspect.a006312

Koldamova, R. P., Lefterov, I. M., Ikonomovic, M. D., Skoko, J., Lefterov, P. I., Isanski, B. A., et al. (2003). 22R-hydroxycholesterol and 9-cis-retinoic acid induce ATP-binding cassette transporter Al expression and cholesterol efflux in brain cells and decrease amyloid beta secretion. J. Biol. Chem. 278, 13244-13256.

Kovac, A., Erickson, M. A., and Banks, W. A. (2011). Brain microvascular pericytes are immunoactive in culture: cytokine, chemokine, nitric oxide, and LRP-1 expression in response to lipopolysaccharide. J. Neuroinflammation 8:139. doi: 10.1186/1742-2094-8-139

Kuhnke, D., Jedlitschky, G., Grube, M., Krohn, M., Jucker, M., Mosyagin, I., et al. (2007). MDR1-P-Glycoprotein 
(ABCB1) mediates transport of Alzheimer's amyloid-beta peptidesimplications for the mechanisms of Abeta clearance at the blood-brain barrier. Brain Pathol. 17, 347-353.

Lam, F. C., Liu, R., Lu, P., Shapiro, A. B., Renoir, J. M., Sharom, F. J., et al. (2001). beta-Amyloid efflux mediated by p-glycoprotein. J. Neurochem. 76, 1121-1128.

Leslie, E. M., Deeley, R. G., and Cole, S. P. (2005). Multidrug resistance proteins: role of P-glycoprotein, MRP1, MRP2, and BCRP (ABCG2) in tissue defense. Toxicol. Appl. Pharmacol. 204, 216-237.

Levy-Lahad, E., Wijsman, E. M., Nemens, E., Anderson, L., Goddard, K. A., Weber, J. L., et al. (1995). A familial Alzheimer's disease locus on chromosome 1. Science 269, 970-973.

Loeb, M. B., Molloy, D. W., Smieja, M., Standish, T., Goldsmith, C. H., Mahony, J., et al. (2004). A randomized, controlled trial of doxycycline and rifampin for patients with Alzheimer's disease. J. Am. Geriatr. Soc. 52, 381-387.

Löscher, W., and Potschka, H. (2005). Blood-brain barrier active efflux transporters: ATP-binding cassette gene family. NeuroRx 2, 86-98.

Lue, L. F., Kuo, Y. M., Roher, A. E., Brachova, L., Shen, Y., Sue, L., et al. (1999). Soluble amyloid beta peptide concentration as a predictor of synaptic change in Alzheimer's disease. Am. J. Pathol. 155, 853-862.

Naert, G., and Rivest, S. (2011). The role of microglial cell subsets in Alzheimer's disease. Curr. Alzheimer Res. 8, 151-155.

Nagele, R. G., D’Andrea, M. R., Lee, H., Venkataraman, V., and Wang, H. Y. (2003). Astrocytes accumulate A beta 42 and give rise to astrocytic amyloid plaques in Alzheimer disease brains. Brain Res. 971, 197-209.

Nalivaeva, N. N., Beckett, C., Belyaev, N. D., and Turner, A. J. (2012). Are amyloid-degrading enzymes viable therapeutic targets in Alzheimer's disease? J. Neurochem. 120, 167-185.

Pan, X. D., Zhu, Y. G., Lin, N., Zhang, J., Ye, Q. Y., Huang, H. P., et al. (2011). Microglial phagocytosis induced by fibrillar $\beta$-amyloid is attenuated by oligomeric $\beta$-amyloid: implications for Alzheimer's disease. Mol.
Neurodegener. 6:45. doi: 10.1186/ 1750-1326-6-45

Panzenboeck, U., Balazs, Z., Sovic, A., Hrzenjak, A., Levak-Frank, S., Wintersperger, A., et al. (2002). ABCA1 and scavenger receptor class B, type I, are modulators of reverse sterol transport at an in vitro blood-brain barrier constituted of porcine brain capillary endothelial cells. J. Biol. Chem. 277, 42781-42789.

Pimentel-Coelho, P. M., and Rivest, S. (2012). The early contribution of cerebrovascular factors to the pathogenesis of Alzheimer's disease. Eur. J. Neurosci. 35, 1917-1937.

Rensink, A. A., Otte-Höller, I., ten Donkelaar, H. J., De Waal, R. M., Kremer, B., and Verbeek, M. M. (2004). Differential gene expression in human brain pericytes induced by amyloid-beta protein. Neuropathol. Appl. Neurobiol. 30, 279-291.

Sagare, A. P., Bell, R. D., and Zlokovic, B. V. (2012). Neurovascular dysfunction and faulty amyloid $\beta$-peptide clearance in Alzheimer disease. Cold Spring Harb. Perspect. Med. 2:a011452. doi: 10.1101/ cshperspect.a011452

Saint-Pol, J., Vandenhaute, E., Boucau, M. C., Candela, P., Dehouck, L., Cecchelli, R., et al. (2012). Brain pericytes ABCAl expression mediates cholesterol efflux but not cellular amyloid- $\beta$ peptide accumulation. J. Alzheimers Dis. 30, 489-503. doi: 10.3233/JAD-2012112090

Selkoe, D. J. (2002). Alzheimer's disease is a synaptic failure. Science 298, 789-791.

Sherrington, R., Rogaev, E. I., Liang, Y., Rogaeva, E. A., Levesque, G., Ikeda, M., et al. (1995). Cloning of a gene bearing missense mutations in early-onset familial Alzheimer's disease. Nature 375, 754-760.

Silverberg, G. D., Miller, M. C., Messier, A. A., Majmudar, S., Machan, J. T., Donahue, J. E., et al. (2010). Amyloid deposition and influx transporter expression at the bloodbrain barrier increase in normal aging. J. Neuropathol. Exp. Neurol. 69, 98-108.

Sisodiya, S. M., Lin, W. R., Harding, B. N., Squier, M. V., and Thom, M. (2002). Drug resistance in epilepsy: expression of drug resistance proteins in common causes of refractory epilepsy. Brain 125, 22-31.

Tokuda, T., Calero, M., Matsubara, E. Vidal, R., Kumar, A., Permanne, B., et al. (2000). Lipidation of apolipoprotein E influences its isoform-specific interaction with Alzheimer's amyloid beta peptides. Biochem. J. 348, 359-365.

Verbeek, M. M., de Waal, R. M., Schipper, J. J., and Van Nostrand, W. E. (1997). Rapid degeneration of cultured human brain pericytes by amyloid beta protein. J. Neurochem. 68, 1135-1141.

Vogelgesang, S., Cascorbi, I., Schroeder, E., Pahnke, J., Kroemer, H. K., Siegmund, W., et al. (2002). Deposition of Alzheimer's betaamyloid is inversely correlated with P-glycoprotein expression in the brains of elderly non-demented humans. Pharmacogenetics 12, 535-541.

Vogelgesang, S., Warzok, R. W., Cascorbi, I., Kunert-Keil, C., Schroeder, E., Kroemer, H. K., et al. (2004). The role of P-glycoprotein in cerebral amyloid angiopathy; implications for the early pathogenesis of Alzheimer's disease. Curr. Alzheimer Res. 1, 121-125.

Wahrle, S. E., Jiang, H., Parsadanian, M., Hartman, R. E., Bales, K. R., Paul, S. M., et al. (2005). Deletion of Abcal increases Abeta deposition in the PDAPP transgenic mouse model of Alzheimer disease. J. Biol. Chem. 280, 43236-43242.

Wahrle, S. E., Jiang, H., Parsadanian, M., Kim, J., Li, A., Knoten, A., et al. (2008). Overexpression of ABCA1 reduces amyloid deposition in the PDAPP mouse model of Alzheimer disease. J. Clin. Invest. 118, 671-682.

Wahrle, S. E., Jiang, H., Parsadanian, M., Legleiter, J., Han, X., Fryer, J. D., et al. (2004). ABCA1 is required for normal central nervous system ApoE levels and for lipidation of astrocyte-secreted apoE. J. Biol. Chem. 279, 40987-40993.

Wilhelmus, M. M., Otte-Höller, I., van Triel, J. J., Veerhuis, R., Maat-Schieman, M. L., Bu, G., et al. (2007). Lipoprotein receptor-related protein-1 mediates amyloid-beta-mediated cell death of cerebrovascular cells. Am. J. Pathol. 171, 1989-1999.
Wolf, A., Bauer, B., and Hartz, A. M. (2012). ABC transporters and the Alzheimer's disease enigma. Front. Psychiatry 3:54. doi: 10.3389/fpsyt. 2012.00054

Wyss-Coray, T., Loike, J. D., Brionne, T. C., Lu, E., Anankov, R., Yan, F., et al. (2003). Adult mouse astrocytes degrade amyloid-beta in vitro and in situ. Nat. Med. 9, 453-457.

Yamada, K., Hashimoto, T., Yabuki, C., Nagae, Y., Tachikawa, M. Strickland, D. K., et al. (2008). The low density lipoprotein receptorrelated protein 1 mediates uptake of amyloid beta peptides in an in vitro model of the blood-brain barrier cells. J. Biol. Chem. 283, 34554-34562.

Zlokovic, B. V. (2005). Neurovascular mechanisms of Alzheimer's neurodegeneration. Trends Neurosci. 28, 202-208.

Zlokovic, B. V. (2008). The blood-brain barrier in health and chronic neurodegenerative disorders. Neuron 57, 178-201.

Zlokovic, B. V. (2011). Neurovascular pathways to neurodegeneration in Alzheimer's disease and other disorders. Nat. Rev. Neurosci. 12, 723-738.

Conflict of Interest Statement: The authors declare that the research was conducted in the absence of any commercial or financial relationships that could be construed as a potential conflict of interest.

Received: 29 December 2012; accepted: 27 February 2013; published online: 13 March 2013.

Citation: ElAli $A$ and Rivest $S$ (2013) The role of $A B C B 1$ and $A B C A 1$ in beta-amyloid clearance at the neurovascular unit in Alzheimer's disease. Front. Physiol. 4:45. doi: 10.3389/fphys. 2013.00045

This article was submitted to Frontiers in Membrane Physiology and Biophysics, a specialty of Frontiers in Physiology. Copyright (c) 2013 ElAli and Rivest. This is an open-access article distributed under the terms of the Creative Commons Attribution License, which permits use, distribution and reproduction in other forums, provided the original authors and source are credited and subject to any copyright notices concerning any third-party graphics etc. 